\title{
MÉTODO ATIVO DE APRENDIZAGEM DE ESTATÍSTICA: UMA EXPERIÊNCIA NOS CURSOS DA UNIRIO
}

\author{
Alexandre Silva, Maria Tereza Serrano Barbosa, Luciane Velasque Maria Beatriz Cunha, \\ Bruno Simões, Steven Ross, Felipe Ribeiro \\ Universidade Federal do Estado do Rio de Janeiro (UNIRIO), Brasil \\ alexandre.silva@uniriotec.br
}

\begin{abstract}
A Estatística é um componente curricular presente em quase todos os cursos de graduação. $O$ uso crescente deste conhecimento é motivado pela necessidade de gerar informações a partir de grandes volumes de dados disponiveis em nossa sociedade cada vez mais informatizada. Neste trabalho serão apresentadas e discutidas as potencialidades de uma metodologia ativa de aprendizado de Estatística utilizando o programa $R$. Tendo como objetivo desenvolver a habilidade de raciocínio, a autonomia e em especial, o pensamento crítico por parte dos estudantes, estimulando-os a tornarem-se responsáveis pelo processo de aprendizagem de Estatística. Como resultado desta metodologia, percebemos que a Estatística tornou-se mais interessante aos olhos dos estudantes, uma vez que estes conseguem visualizar a importância e utilidade desse conhecimento na carreira escolhida.
\end{abstract}

\section{INTRODUÇÃO}

Desde metade do século XX, vivenciamos um aumento considerável da demanda por informação, tendo como consequência o aumento na exigência por conhecimentos em estatística em todas as áreas do conhecimento. Isso se deve principalmente pela necessidade de gerar informações a partir da divulgação de grandes volumes de dados em uma sociedade cada vez mais informatizada. A transformação tecnológica não somente nos trouxe o aumento na capacidade de processamento dos computadores, mas também uma nova maneira de se pensar o processo de ensino/aprendizagem.

Preocupados em trazer essas discussões para nossa prática em sala de aula e fazendo uma auto-avaliação das disciplinas de Estatística lecionadas por nós, para os mais diversos cursos da universidade, percebemos um sentimento de frustração em comum, uma vez que mesmo os alunos mais dedicados não conseguiam fazer conexões da Estatística com as outras disciplinas, não reconheciam aplicações da Estatística em sua futura formação e não se achavam aptos a realizar análises e discussões de dados durante o trabalho de conclusão. Assim, o grupo de professores vem desde o segundo semestre de 2012 discutindo e implementando mudanças na metodologia de ensino.

Em setembro de 2012, informamos oficialmente à comunidade da Unirio que iríamos adotar uma nova metodologia para o ensino de Estatística. Para a apresentação, foram convidados todos os diretores das escolas que possuem a Estatística como componente curricular e também professores interessados nessas discussões. Esse encontro tinha como principal objetivo apresentar as propostas de alteração na relação ensino-aprendizagem de Estatística, de forma a inserir atividades direcionadas a uma Pedagogia Ativa, tais como: as metodologias baseadas em problemas (Bouhuijs, Schmidt, \& Berkel, 1993; Boud \& Feletti, 1998; Berbel, 1998; Cyrino \& Toralles-Pereira, 2004) e/ou em metodologias baseada em projetos (Thomas, 2000; Santoro, 2000), buscando que tanto os problemas ou projetos fossem ancorados nas diversas áreas de atuação dos cursos que tenham a estatística na matriz curricular.

$\mathrm{Na}$ proposta da nova metodologia de ensino de Estatística, havia a necessidade da utilização de programas computacionais. Optamos pelo programa R, por ser livre o que permite que os estudantes possam baixar em seus computadores pessoais, de código aberto possibilitando a criação de novos pacotes, extremamente poderoso e flexível do ponto de vista de análise estatística e com possibilidade de diferentes interfaces facilitando o processo de ensino/aprendizagem dos alunos com diferentes níveis de conhecimento em informática.

Além de aprenderem a utilizar uma ferramenta computacional na execução das atividades de análise de dados, nessa nova metodologia os estudantes são desafiados a elaborarem um projeto que cobrisse todas as etapas necessárias a uma pesquisa quantitativa: i) planejamento do estudo, ii) construção de questionário, iii) coleta de dados, iv) análise de dados, v) conclusão, vi) elaboração

In: M.A. Sorto (Ed.), Advances in statistics education: developments, experiences and assessments. Proceedings of the Satellite conference of the International Association for Statistical Education (IASE), July 2015, Rio de Janeiro, Brazil. 
de relatório, vii) apresentação oral e/ou em formato pôster. Além disto, eram estimulados a trabalhar em grupo e realizar revisões de literatura.

Neste trabalho serão apresentadas e discutidas duas experiências realizadas na UNIRIO, em ambos os casos metodologia ativa de aprendizagem de Estatística foram utilizadas nos mais diversos cursos de serviço em que a Estatística é disciplina semestral e obrigatória. Ressaltando as potencialidades de uma metodologia ativa de aprendizado de Estatística em cursos de graduação utilizando o programa R.

\section{MÉTODO}

A metodologia tem como objetivos desenvolver a habilidade de raciocínio e, em especial, o pensamento crítico por parte dos estudantes e incentivar sua autonomia, tornando-os atores principais no processo de aprendizagem e exige, para sua aplicação qualificada, uma parceria com docentes de departamentos nos quais a Estatística é componente curricular.

Nessa nova metodologia, os estudantes participam de uma experiência prática que envolve o conhecimento e aplicação dos principais conceitos relacionadas às diversas etapas de um estudo: i) identificação de um problema e definição de hipóteses; ii) o planejamento de uma coleta de dados, iii) elaboração de instrumentos de coleta ou de Sistemas de Informações com dados reais que possam responder às hipóteses levantadas; iv) Coleta e criação do Banco de Dados para análise; v) Análise dos dados e discussão dos resultados com base nos conceitos e técnicas estatísticas apresentados em sala de aula. Consideramos também fundamental, como parte integrada da nova metodologia, a utilização do programa $\mathrm{R}$ e também de outros programas livres. Ao final do semestre é realizado um grande evento para a apresentação dos resultados.

Estas etapas são acompanhadas de perto pelo professor e utilizadas como motivação para os encontros em sala de aula. Dessa forma, há uma mudança no papel do professor deixando de ser o único detentor do conhecimento e passa a ser visto pelos estudantes como um orientador, um facilitador do processo de aprendizagem. Estatística:

Abaixo serão detalhadas duas experiências utilizando metodologia ativa no ensino de

\section{Experiência 1:}

Esta experiência foi aplicada por quatro professores de Estatística no segundo semestre de 2012 e contou com a participação de estudantes dos mais diversos cursos (Engenharia de produção, Sistemas de Informação, Biblioteconomia, Pedagogia, Enfermagem, Nutrição, Ciências Biológicas, Biomedicina).

O tema único proposto a todos os cursos foi: O impacto do Exame Nacional do Ensino Médio (ENEM) e da Lei de Cotas no perfil dos estudantes.

A seguir são apresentadas as etapas desenvolvidas durante o semestre:

Etapa 1: Os estudantes foram estimulados a iniciarem as discussões por meio de trechos de dois textos e dois questionamentos (citados abaixo):

Texto 1

"Quando foi criado, em 1998, o Exame Nacional do Ensino Médio (Enem) era uma avaliação voluntária que tinha como objetivo medir as competências e habilidades adquiridas pelos estudantes ao final do ensino médio. Desde sua reformulação, em 2009, o Enem ganhou novas funções. A mais direta é que o exame passou a ser usado como instrumento de seleção em algumas universidades. Outro papel seria o de induzir um currículo para o ensino médio nas escolas - a hipótese é usada pelo Ministério da Educação para justificar o aumento das notas no exame entre 2009 e 2010. No periodo, a média dos estudantes no país passou de 501,5 para 511,2. "(Deborah Ouchana)

Texto 2

"Os 6,4 milhões de vestibulandos inscritos no Enem deste ano deverão pensar nas suas chances de entrar para uma universidade federal já levando em consideração a Lei das Cotas, caso o projeto seja mesmo sancionado pela presidente Dilma Rousseff. De acordo com o texto, aprovado pelo Senado, as universidades federais e Escolas técnicas do país serão obrigadas a reservar 50\% de suas vagas para Alunos da rede pública de Ensino médio. As instituições terão quatro anos para se adequar à nova realidade, mas precisarão garantir pelo menos $25 \%$ de suas 
vagas aos cotistas já a partir do próximo processo de seleção, cujas provas acontecem dias 3 e 4 de novembro "(O Globo em 11/08/2012).

1. A adoção pelo ingresso na UNIRIO apenas pelo ENEM causou impacto na sala de aula ?

2. Como medir o impacto da Lei de cotas na mudança do perfil racial e sócio-econômico dos ingressantes na UNIRIO?

Etapa 2: Os alunos foram divididos em grupos e pesquisaram outros textos, além disto, nesta etapa, foram realizadas discussões ou júris simulados a respeito da Lei de Cotas, Exame Nacional do Ensino Médio (ENEM) e perfil de estudante;

Etapa 3: Tomando como população alvo do estudo todos os estudantes dos cursos, definiuse os objetivos gerais e específicos de cada grupo;

Etapa 4: Foram definidos os instrumentos de coleta de dados, com questões gerais e específicas;

Etapa 5: Consolidação de um módulo geral do questionário, único para todos os cursos e de um questionário para cada curso com suas questões específicas; dados;

Etapa 6: Coleta, digitação (alguns grupos optaram por aplicação on line) e análise de

Etapa 7: Execução de relatório e apresentação, em sala de aula, dos resultados;

Etapa 8: Consolidação de uma única apresentação por cursos e apresentação final em auditório.

\section{Experiência 2:}

Esta experiência foi realizada no segundo semestre de 2014 e participaram seis professores de Estatística e mais de 200 alunos dos diversos cursos de graduação da UNIRIO (Engenharia de produção, Sistemas de Informação, Matemática, Enfermagem, Nutrição, Ciências Biológicas, Ciências Ambientais, Biomedicina, Biblioteconomia, Administração Pública, Ciências Políticas, Turismo).

As turmas foram divididas em grupos e desafiadas a pesquisarem temas de interesse comum aos integrantes. Foi proposto que os alunos pesquisassem dados disponíveis na internet, sendo utilizado para este fim páginas como: IBGE, INEP, DATA SUS, IPEA, armazém dos dados, dentre outros. Desta forma, os estudantes puderam reservar mais tempo para as análises, pois não havia a necessidade de construir instrumento de coleta, aplicar questionário e tabular os dados.

Assim como na Experiência 1, detalhada acima, foi proposto um projeto que cobrisse todo o conteúdo do curso, passando por definição de objetivos, revisão de literatura, análise estatística, elaboração de relatório e apresentação.

As apresentações foram realizadas em formato oral em sala de aula e em formato pôster em um evento de encerramento da disciplina. $\mathrm{O}$ evento ocorreu nos períodos da manhã, tarde $\mathrm{e}$ noite eram reservados momentos em que era aberta a palavra para que os alunos pudessem expor suas opiniões, comentários e sugestões sobre o curso, sobre a metodologia, sobre o trabalho. Depois deste momento de conversa os alunos posicionavam-se ao lado do pôster e aguardava a avaliação de um professor.

\section{RESULTADOS}

Novas metodologias de ensino de Estatística vêm sendo discutidas e implementadas na UNIRIO desde 2012 e a cada novo semestres há uma ampla discussão sobre as técnicas aplicadas, mas de forma geral podemos pontuar alguns resultados:

- Os professores colaboradores tornam-se parceiros em publicações científicas;

- Aos olhos dos alunos a Estatística torna-se mais interessante, uma vez que, estes conseguem visualizar a importância e utilidade deste conhecimento na carreira escolhida;

- Os estudantes tornam-se mais preparados para aplicar os conceitos estatísticos no mundo real;

- Conseguem enxergar conexões e aplicações de estatística nas demais matérias do curso;

- Existe a possibilidade dos alunos irem além do conteúdo inicialmente determinado pela disciplina;

- Os professores compartilham constantemente suas percepções e atividades;

- Permite que os alunos vejam os resultados alcançados pelos demais colegas. 


\section{DISCUSSÃO}

O uso de programas estatísticos tem sido um grande aliado na educação, facilitando o sistema de ensino/aprendizagem da Estatística, tornando a disciplina mais atrativa, além de gerar resultados confiáveis, em tempo mínimo, de análises complexas e elaboradas. O programa R é um bom exemplo desse poder computacional, vem ganhando cada vez mais espaço e caindo no gosto do usuário por ser livre, gratuito e de código aberto.

Permitir que o aluno, durante o curso de graduação, tenha contacto com a aplicação das técnicas estatísticas em sua área de formação profissional, torna a disciplina de Estatística Aplicada mais acessível e prazerosa, possibilitando uma ampliação da visão de formação do estudante. Isto permite que este não somente aprenda a criar as hipóteses de interesse científico, mas que também, possa testá-las, usando todo o ferramental aprendido durante a disciplina.

Acreditamos que com esta metodologia o estudante tem tido a oportunidade de se desenvolver e adquirir mais autonomia estando mais preparado para atuar como um profissional ao término de sua graduação, além disso ele tem sido estimulado a apresentar os resultados da disciplinas em encontros científicos.

No Experimento 2 foi proposto aos estudantes uma pesquisa de dados disponíveis na internet, diferentemente da proposta apresentada na Experiência 1, já que o processo de elaboração do instrumento e coleta de dados são atividades que demandam muito tempo e pode comprometer o resultado final do trabalho, uma vez que restará pouco tempo para a elaboração das análises.

Estas experiências tem exigido que o grupo de docentes de Estatística atravessasse barreiras físicas de suas salas e de seu departamento, para buscar parcerias com outros docentes dos cursos que possuem o componente de Estatística: Biologia, Biomedicina, Biblioteconomia, Pedagogia, Engenharia de Produção, Enfermagem, Nutrição, Sistema de Informação, Administração, Ciências Políticas e Turismo. Com isso, além de conseguirmos estudantes mais interessados e motivados com a Estatística, nós professores aprendemos sobre as profissões e utilidades práticas da Estatística sendo assim um incentivo a interdisciplinaridade.

\section{REFERÊNCIAS}

Berbel, N. N. (1998). A problematização e a aprendizagem baseada em problemas: diferentes termos ou diferentes caminhos? Interface - Comunicação, Saúde, Educação, 2(2).

Boud, D., \& Feletti, G. (1998). The Challenge of Problem-Based Learning, Kogan Page.

Bouhuijs, P., Schmidt, H., \& Berkel, H. (1993) Problem-Based Learning as an Educational Strategy. Maastricht: Network Publications.

Cyrino, E. G., Toralles-Pereira, M. L. (2004). Trabalhando com estratégias de ensino-aprendizado por descoberta na área da saúde: a Problematização e a aprendizagem baseada em problemas, Caderno de Saúde Pública, Rio de Janeiro, 20(3), 780-788.

Santoro, F. M., Borges, M. R. S., \& Santos, N. (2000). An Infrastructure to Support the Development of Collaborative Project-Based Learning Environments. In IEEE Press Proceedings of International Workshop on Groupware-CRIWG'00, Madeira, Portugal, pp. 7885.

Thomas, J. W. (2000). A review of research on project-based learning. disponível em http://www.newtechnetwork.org.590elmp01.blackmesh.com/sites/default/files/dr/pblresearch2 .pdf, acessado em 23/02/2015. 